\title{
Development of microsatellite markers for the Japanese endemic conifer Thuja standishii and transfer to other East Asian species
}

\author{
James R. P. Worth ${ }^{1 *}$, K. S. Chang ${ }^{2}$, Y.-H. Ha ${ }^{2}$ and Aili Qin ${ }^{3}$
}

\begin{abstract}
Objective: Design polymorphic microsatellite loci that will be useful for studies of the genetic diversity, gene-flow and reproduction in the Japanese endemic conifer Thuja standishii and test the transferability of these loci to the two other East Asian species, T. sutchuenensis and T. koraiensis.

Results: Fifteen loci were developed which displayed 3 to 21 alleles per locus (average $=9.2$ ) among 97 samples from three populations of T. standishii. Observed heterozygosity for all samples varied between 0.33 and 0.75 (average $=0.54)$ while expected heterozygosity values were higher with an average over the 15 loci of 0.62 (0.37-0.91). Low multi-locus probability of identity values $(<0.00002)$ indicate that these markers will be effective for identifying individuals derived from clonal reproduction. All 15 loci amplified in 13 samples of T. sutchuenensis, the sister species of T. standishii, with 1 to 11 alleles per locus (average $=4.33$ ) while 13 loci amplified in four samples of the more distantly related $T$. koraiensis with 1 to 5 alleles per locus (average $=2.15$ ).
\end{abstract}

Keywords: China, Conifer, Japanese arbor-vitae, Korea, Nuclear microsatellites, Thuja

\section{Introduction}

Thuja is a small Cupressaceae genus consisting of five extant species with three species in East Asia and two in North America [6]. Thuja standishii (Gordon) Carriere (kurobe or nezuko in Japanese and Japanese arbor-vitae in English) is endemic to Japan where it has a scattered distribution from $40.67^{\circ} \mathrm{N}$ to $33.49^{\circ} \mathrm{N}$ on the islands of Honshu, Shikoku and Dogo (Shimane Prefecture). The species is most commonly a component of subalpine forests but also occurs in a variety of habitats including warm temperate forest (rarely), cool temperate forest, moorland and near the alpine zone. The species can grow as a single-stemmed tree up to $35 \mathrm{~m}$ tall but occurs as a multi-stemmed shrub under $1 \mathrm{~m}$ tall at the maximum

\footnotetext{
*Correspondence: jrpw2326@affrc.go.jp

${ }^{1}$ Department of Forest Molecular Genetics and Biotechnology, Forestry and Forest Products Research Institute, Matsunosato 1, Tsukuba, Ibaraki 305-8687, Japan

Full list of author information is available at the end of the article
}

limit of its elevational range [15]. It can purportedly reach a great age with trunks up to $3.5 \mathrm{~m}$ in diameter (Giant Tree Database, Biodiversity Center of Japan (http://kyoju .biodic.go.jp)) and individuals over 1000 years old.

Unlike most other Cupressaceae conifers of Japan, $T$. standishii has received little research attention with basic information on its conservation (including the impact of past logging), reproductive biology and genetic diversity, lacking. The rarity of forest dominated by $T$. standishii and its current insignificant role in forestry probably underlies this lack of research. However, the species is undoubtedly an important part of Japan's biodiversity and cultural heritage. For example, it is one of Japan's five precious timber trees (Kiso go-boku) that from the early 18 th century were strictly protected from cutting in the Kiso region of central Honshu [8] and, in some parts of Japan, forests containing T. standishii are considered to represent the most untouched forests remaining in the landscape (e.g. [13]. Small population size and geographic isolation, its vulnerability to ring barking by deer 
and the impacts of past logging [15] has resulted in some populations being of conservation concern, especially in western Japan where the species is very rare [15]. One key aspect of the species biology that is poorly understood is the role of asexual reproduction in its regeneration. However, similarly to two other Japanese Cupressaceae conifers, Thujopsis dolobrata and C. pisifera that have been proven to regenerate clonally $[3,4], T$. standishii also forms dense understory banks of juveniles (Worth personal observation) which may be clonally derived.

In the current age of genomics, microsatellites retain a vital role in biology due to their high information content, utility in a wide range of genetic applications and cost-efficient nature [5]. This study describes the development of Expressed Sequence Tagged (EST) nuclear microsatellite markers for $T$. standishii using next generation sequencing. These markers will be useful molecular tools to inform the conservation of this species via studies of its range-wide genetic diversity, gene flow and reproductive biology. In addition, the transferability of the markers was tested in the two other East Asian species for which no microsatellite markers have yet been developed including the Chinese endemic Thuja sutchuenensis, the sister species of T. standishii [7, 10], and T. koraiensis.

\section{Main text}

\section{Materials and methods}

Total RNA was extracted from an individual of $T$. standishii collected from the Forestry and Forest Products Research Institute Arboretum using a plant RNA isolation mini kit (Agilent Technologies, USA). An RNAseq data set was constructed by the Beijing Genomics Institute on an Illumina HiSeq4000 platform. The $T$. standishii RNA-seq data consisted of 38,076,160 pairedend reads of $100 \mathrm{bp}$ length. De novo assembly was undertaken in CLC Genomics Workbench 8.5.1 and the 53,614 resultant contigs $(N 50=1503 \mathrm{bp})$ were mined for microsatellite regions. Primers were developed bordering these regions with default settings using PrimerPro (http://webdocs.cs.ualberta.ca/ yifeng/primerpro/). Microsatellites were selected if the number of tandem repeat units was greater than eight and if the microsatellite was located less than $25 \mathrm{bp}$ from the beginning or end of the contig. These criteria resulted in 64 microsatellite primer pairs which were trialled for amplification in four samples. A total of 36 primer pairs successfully amplified and were subsequently tested for size heterogeneity in eight samples representative of the species range. For all loci, the forward primer was synthesized with one of three different M13 sequences (5'-GCCTCCCTCGCG CCA-3', 5'-GCCTTGCCAGCCCGC-3', and 5'-CAG GACCAGGCTACCGTG-3'), and the reverse was tagged with a pig-tail ( $5^{\prime}$-GTTTCTT-3'; [2]). The PCR reactions were performed following the standard protocol of the Qiagen Multiplex PCR Kit (Qiagen, Hilden, Germany), and consisted of a $10 \mathrm{uL}$ reaction volume, containing approximately $5 \mathrm{ng}$ of DNA, $5 \mathrm{uL}$ of $2 \times$ Multiplex PCR Master Mix, and $0.06 \mathrm{uM}$ of forward primer, $0.1 \mathrm{uM}$ of reverse primer, and $0.08 \mathrm{uM}$ of fluorescently labelled M13 primer. The PCR thermocycle consisted of an initial denaturation at $95^{\circ} \mathrm{C}$ for $3 \mathrm{~min}$; followed by 35 cycles of $95{ }^{\circ} \mathrm{C}$ for $30 \mathrm{~s}, 60^{\circ} \mathrm{C}$ for $3 \mathrm{~min}, 68^{\circ} \mathrm{C}$ for $1 \mathrm{~min}$; and a 20 min extension at $68^{\circ} \mathrm{C}$. The PCR products were separated by capillary electrophoresis on an ABI3130 Genetic Analyzer (Life Technologies, Waltham, MA, USA) with the GeneScan 600 LIZ Size Standard (Life Technologies) and genotyping was done in GeneMarker (SoftGenetics, LLC, PA, USA). Overall, 15 loci were found to amplify reliably, display polymorphism and were readily scorable. The genetic variability of these 15 markers were tested in three populations from Atebi Daira Small Bird Forest, Mt Chausu Nature Park, in Nagano Prefecture $\left(35.2286^{\circ} \mathrm{N}\right.$, $\left.137.6673^{\circ} \mathrm{E}\right)$, Mt Torigata in Kouchi Prefecture $\left(33.4936^{\circ}\right.$ $\mathrm{N}, 133.0638^{\circ} \mathrm{E}$ ) and Mt Yamizo in Fukushima Prefecture $\left(36.9343^{\circ} \mathrm{N}, 140.2679^{\circ} \mathrm{E}\right)$. The 15 primer pairs were also tested in 13 samples of $T$. sutchuenensis and four of $T$. koraeinsis (Additional file 1: Table S1). Genetic analyses were undertaken in GenAlEx 6.5 [9] and Genepop 4.2 [11]. In addition, a similarity search of the contigs containing the 15 loci was conducted by the BLASTX algorithm [1] against the National Center for Biotechnology Information (NCBI) non-redundant protein sequences (nr) database.

The multi locus probability of identity (PID) for the 15 markers, that is, the probability that two individuals drawn at random from a population will have the same genotype [14], was calculated in Gimlet version 1.3.3 [12] using all 97 samples from the three population of $T$. standishii. Three PID estimates outlined by Waits et al. [14] were estimated: biased PID, which assumes individuals mate randomly; unbiased PID, which corrects for sampling a small number of individuals and, sibs PID, which assumes the population is composed of siblings.

\section{Results}

In T. standishii, the 15 loci (Table 1) displayed 3 to 21 alleles over the three populations with an average of 9.2 alleles per locus (Table 2). Overall observed heterozygosity varied between 0.33 and 0.75 (average $=0.54$ ) while expected heterozygosity values were generally higher (0.37-0.91 with an average of 0.62). At the population level, the number of alleles observed per locus varied from 2 to 15 (average $=5.43$ ) with six loci showing more than four alleles in each of the three populations. No significant deviations from Hardy-Weinberg 
Table 1 Characteristics of the 15 microsatellite markers developed for Thuja standishii

\begin{tabular}{|c|c|c|c|c|c|c|}
\hline Locus & Primer $\left(5^{\prime}-3^{\prime}\right)$ & Repeat motif & $\begin{array}{l}\text { Allele size } \\
\text { range } \\
\text { (bp) }\end{array}$ & BlastX top hit description & E-value & Genbank accession \\
\hline Kurobe_18480 & $\begin{array}{l}\text { F:TCAGGACCCCAACAAATAAA } \\
\text { R: GATGCTGGAGATGGTATTTCG }\end{array}$ & (AT)9 & $135-189$ & Unknown [Picea sitchensis] ABR17033.1 & $3 \mathrm{E}-95$ & MN170833 \\
\hline Kurobe_2969 & $\begin{array}{l}\text { F: ACACAATCTTGCCCAGAAGC } \\
\text { R: ACACAATCTTGCCCAGAAGC }\end{array}$ & $(\mathrm{TA}) 8$ & $269-291$ & $\begin{array}{l}\text { WRI2 [Larix gmelinii var. olgensis } \times \text { L. } \\
\text { kaempferi] AJP75043.1 }\end{array}$ & 0 & MN170828 \\
\hline Kurobe_23700 & $\begin{array}{l}\text { F: CCGACGCCTCTACATTCATT } \\
\text { R: ATGGAAAAGAGGCAGAGCAA }\end{array}$ & $(\mathrm{TCT}) 10$ & $250-268$ & $\begin{array}{l}\text { Hypothetical protein } \\
\text { MARPO_0043s0052 [Marchantia } \\
\text { polymorpha] PTQ39804.1 }\end{array}$ & $2 E-39$ & MN170835 \\
\hline Kurobe_44557 & $\begin{array}{l}\text { F: GATCCCTTTTGATGGGTTCA } \\
\text { R:TTATCCCCAACTTCAGCGAG }\end{array}$ & $(\mathrm{TC}) 11$ & $313-349$ & - & - & MN170841 \\
\hline Kurobe_15129 & $\begin{array}{l}\text { F: TTAACATCCACCAATGGCAA } \\
\text { R: CAAATGCATGGAATGTGGTC }\end{array}$ & (TC)12 & $205-233$ & Unknown [Picea sitchensis] ABK22564.1 & $9 \mathrm{E}-66$ & MN170831 \\
\hline Kurobe_16758 & $\begin{array}{l}\text { F: TGCAACGTCATAACCACGAT } \\
\text { R: CACCCTTCTAGAGCTGGTCG }\end{array}$ & $(\mathrm{CT}) 8$ & $272-283$ & $\begin{array}{l}\text { CYP866B7 [Taxus chinensis] } \\
\text { ATG30002.1 }\end{array}$ & 0 & MN170832 \\
\hline Kurobe_6943 & $\begin{array}{l}\text { F: CTACGTCTTAGCCTCCACGC } \\
\text { R: ATGCCATACTGGGGTCTGAG }\end{array}$ & (CT)11 & 159-169 & $\begin{array}{l}\text { Early nodulin-like protein } 2 \text { [Amborella } \\
\text { trichopoda] XP_011628802.2 }\end{array}$ & $4 \mathrm{E}-37$ & MN170830 \\
\hline Kurobe_23263 & $\begin{array}{l}\text { F: CCAGGCCCTAATTTCCACTC } \\
\text { R: CCATGGCACATGGATACAGA }\end{array}$ & $(\mathrm{AG}) 10$ & $290-314$ & - & - & MN170834 \\
\hline Kurobe_51603 & $\begin{array}{l}\text { F: CAAAGCAACAGAGCCAACAA } \\
\text { R:AAATAGGGTGCTGCAGGTTG }\end{array}$ & (TG)13 & $162-201$ & - & - & MN170842 \\
\hline Kurobe_31302 & $\begin{array}{l}\text { F: TCCCAAGTCTGGGGCAGT } \\
\text { R: GTCACAGTCGGGAGCAATTT }\end{array}$ & $(\mathrm{GT}) 8$ & $264-274$ & - & - & MN170836 \\
\hline Kurobe_38308 & $\begin{array}{l}\text { F:TTTGCTGAAACCCAGGAATC } \\
\text { R:CCCCATATGGAAGAAGATCC }\end{array}$ & (TG) 11 & $272-297$ & - & - & MN170837 \\
\hline Kurobe_41636 & $\begin{array}{l}\text { F:TTGAACTTTGCAGTGGGAAA } \\
\text { R: GAACCAGACAGGAATCGGAA }\end{array}$ & $(C A) 8$ & $157-165$ & - & - & MN170839 \\
\hline Kurobe_42400 & $\begin{array}{l}\text { F:TTCACACAAGGGCCTACTCC } \\
\text { R: GCCGACAGGTCTCTTAGCAC }\end{array}$ & (TC)9 & $254-272$ & - & - & MN170840 \\
\hline Kurobe_40825 & $\begin{array}{l}\text { F: TTATCCCATGAGCGTGCTTT } \\
\text { R:TAGGTGCGGTGACTATGCAG }\end{array}$ & $(\mathrm{CT}) 8$ & $232-276$ & - & - & MN170838 \\
\hline Kurobe_4219 & $\begin{array}{l}\text { F: ACGCATCGGACAGTCGTATT } \\
\text { R: CCGTGCAGAACCAAAGAAAT }\end{array}$ & (TC)8 & $276-306$ & $\begin{array}{l}\text { MACPF domain-containing pro- } \\
\text { tein At4g24290 [Morus notabilis] } \\
\text { XP_010087924.1 }\end{array}$ & 0 & MN170829 \\
\hline
\end{tabular}

- denotes that no BlastX hits were found

equilibrium expectations were detected for any loci except for Kurobe_4219 in the Atebi Daira and Mt Yamizo populations $(\mathrm{P} \leq 0.0004)$. Additionally, allele frequencies appeared independent among loci with no significant linkage disequilibrium detected after Bonferroni correction.

Multi-locus probability of identity values were below the threshold value of 0.01 considered by Waits et al. [14] to be required to reliably distinguish between individual genotypes, even under the sibs PID (Additional file 1: Table S2). This indicates that our markers will be effective for both identifying individuals derived from clonal reproduction and sexually derived individuals in populations even where inbreeding is prevalent.

All 15 loci amplified in T. sutchuenensis (two loci being monomorphic) with 1 to 11 alleles per locus (average $=4.33$ ) while average observed and expected heterozygosity were 0.43 and 0.48 , respectively (Table 3 ). On the other hand, only 13 loci amplified in T. koraiensis with three loci being monomorphic. In this species, 1 to 5 alleles per locus (average $=2.15$ ) were found with average observed and expected heterozygosity of 0.44 and 0.31 , respectively (Table 3 ).

\section{Discussion}

The development of EST microsatellites for Thuja standishii will enable new genetic research into this important Japanese endemic conifer including studies of range-wide level genetic diversity and gene flow and also stand-level processes such as inbreeding and clonality. The development of molecular markers may help to foster research into this species, which because of its wide ecological range, from warm temperate forests to near the alpine zone, is an ideal species to investigate 
Table 2 Genetic diversity of the 15 polymorphic nuclear microsatellites assessed across the three populations of Thuja standishii

\begin{tabular}{|c|c|c|c|c|c|c|c|c|c|c|c|c|}
\hline \multirow[t]{2}{*}{ Locus } & \multicolumn{3}{|c|}{ Atebi Daira (32) } & \multicolumn{3}{|c|}{ Mt Torigata (31) } & \multicolumn{3}{|c|}{ Mt Yamizo (34) } & \multicolumn{3}{|c|}{ All (97) } \\
\hline & $\mathrm{Na}$ & Ho & $\mathrm{He}$ & $\mathrm{Na}$ & Ho & $\mathrm{He}$ & $\mathrm{Na}$ & Ho & He & $\mathrm{Na}$ & Ho & $\mathrm{He}$ \\
\hline Kurobe_18480 & 13 & 0.75 & 0.77 & 11 & 0.81 & 0.82 & 8 & 0.38 & 0.43 & 21 & 0.64 & 0.77 \\
\hline Kurobe_2969 & 6 & 0.53 & 0.45 & 5 & 0.52 & 0.60 & 7 & 0.85 & 0.77 & 9 & 0.64 & 0.75 \\
\hline Kurobe_23700 & 5 & 0.78 & 0.77 & 5 & 0.42 & 0.38 & 6 & 0.59 & 0.57 & 7 & 0.60 & 0.66 \\
\hline Kurobe_44557 & 14 & 0.68 & 0.89 & 9 & 0.68 & 0.73 & 15 & 0.88 & 0.88 & 21 & 0.75 & 0.91 \\
\hline Kurobe_15129 & 7 & 0.66 & 0.71 & 2 & 0.03 & 0.03 & 5 & 0.68 & 0.69 & 8 & 0.46 & 0.63 \\
\hline Kurobe_16758 & 4 & 0.50 & 0.51 & 3 & 0.29 & 0.26 & 4 & 0.85 & 0.73 & 7 & 0.56 & 0.60 \\
\hline Kurobe_6943 & 3 & 0.28 & 0.30 & 3 & 0.65 & 0.51 & 4 & 0.35 & 0.33 & 7 & 0.42 & 0.50 \\
\hline Kurobe_23263 & 2 & 0.41 & 0.46 & 3 & 0.48 & 0.44 & 3 & 0.38 & 0.51 & 4 & 0.42 & 0.52 \\
\hline Kurobe_51603 & 7 & 0.75 & 0.75 & 3 & 0.55 & 0.54 & 8 & 0.82 & 0.70 & 9 & 0.71 & 0.72 \\
\hline Kurobe_31302 & 3 & 0.63 & 0.55 & 3 & 0.52 & 0.51 & 2 & 0.12 & 0.11 & 3 & 0.41 & 0.42 \\
\hline Kurobe_38308 & 6 & 0.59 & 0.66 & 3 & 0.55 & 0.45 & 5 & 0.50 & 0.58 & 9 & 0.55 & 0.61 \\
\hline Kurobe_41636 & 2 & 0.41 & 0.36 & 2 & 0.39 & 0.46 & 3 & 0.21 & 0.21 & 4 & 0.33 & 0.37 \\
\hline Kurobe_42400 & 7 & 0.50 & 0.48 & 5 & 0.58 & 0.53 & 6 & 0.38 & 0.36 & 9 & 0.48 & 0.46 \\
\hline Kurobe_40825 & 7 & 0.50 & 0.63 & 6 & 0.71 & 0.71 & 5 & 0.68 & 0.58 & 11 & 0.63 & 0.73 \\
\hline Kurobe_4219 & 4 & 0.28 & 0.51 & 6 & 0.61 & 0.57 & 6 & 0.62 & 0.70 & 9 & 0.51 & 0.61 \\
\hline Average & 6.00 & 0.55 & 0.59 & 4.60 & 0.52 & 0.50 & 5.80 & 0.55 & 0.54 & 9.20 & 0.54 & 0.62 \\
\hline
\end{tabular}

$\mathrm{Na}$ the number of alleles, $H_{o}$ observed heterozygosity, $H_{e}$ expected heterozygosity

Table 3 Genetic diversity of the 15 microsatellite loci in T. sutchuenensis and T. koraiensis

\begin{tabular}{|c|c|c|c|c|c|c|}
\hline \multirow[t]{2}{*}{ Locus } & \multicolumn{3}{|c|}{ T. sutchuenensis (13) } & \multicolumn{3}{|c|}{ T. koraiensis (4) } \\
\hline & $\mathrm{Na}$ & Ho & $\mathrm{He}$ & $\mathrm{Na}$ & Ho & $\mathrm{He}$ \\
\hline Kurobe_18480 & 7 & 0.46 & 0.80 & 1 & 0.00 & 0.00 \\
\hline Kurobe_2969 & 7 & 0.61 & 0.79 & 2 & 1.00 & 0.50 \\
\hline Kurobe_23700 & 3 & 0.15 & 0.14 & 2 & 0.25 & 0.22 \\
\hline Kurobe_44557 & 11 & 0.61 & 0.89 & 3 & 0.50 & 0.41 \\
\hline Kurobe_15129 & 6 & 0.69 & 0.76 & 2 & 0.25 & 0.22 \\
\hline Kurobe_16758 & 4 & 0.69 & 0.56 & - & - & - \\
\hline Kurobe_6943 & 1 & 0.00 & 0.00 & - & - & - \\
\hline Kurobe_23263 & 3 & 0.38 & 0.33 & 2 & 0.50 & 0.50 \\
\hline Kurobe_51603 & 4 & 0.38 & 0.38 & 5 & 1.00 & 0.75 \\
\hline Kurobe_31302 & 1 & 0.00 & 0.00 & 2 & 0.75 & 0.47 \\
\hline Kurobe_38308 & 6 & 0.61 & 0.69 & 2 & 0.25 & 0.22 \\
\hline Kurobe_41636 & 2 & 0.46 & 0.43 & 2 & 0.25 & 0.22 \\
\hline Kurobe_42400 & 2 & 0.31 & 0.26 & 1 & 0.00 & 0.00 \\
\hline Kurobe_40825 & 6 & 0.69 & 0.80 & 1 & 0.00 & 0.00 \\
\hline Kurobe_4219 & 2 & 0.38 & 0.39 & 3 & 1.00 & 0.59 \\
\hline Average & 4.33 & 0.43 & 0.48 & 2.15 & 0.44 & 0.31 \\
\hline
\end{tabular}

- denotes that the loci did not amplify

ecological and genetic processes under strongly contrasting climates.

The transferability of the 15 loci was consistent with the phylogenetic relationships of the East Asian Thuja [7, 10]. Thus, all 15 loci successfully amplified in the sister species of T. standishii, T. sutchuenensis, and displayed considerable allelic diversity with up to 11 alleles per locus. These loci, therefore, may be particularly applicable for use in genetic studies of this geographically restricted endangered species [16]. In contrast, two of the fifteen loci did not amplify in the more distantly related T. koraiensis and the number of alleles per locus (ranging 
from 1 to 5 alleles) was low although this low allelic diversity is likely to also be due to the low number of samples tested.

\section{Limitations}

- The number of published microsatellite markers may be too low for optimal performance of some genetic analyses.

- These microsatellite loci have not been tested in the two North American species, T. plicata and T. occidentalis.

- We did not afford much time optimizing loci, therefore some polymorphic loci that may have worked with further effort may have been excluded.

\section{Supplementary information}

Supplementary information accompanies this paper at https://doi. org/10.1186/s13104-019-4716-z.

Additional file 1: Table S1. Sampling information for T. sutchuenensis and T. koraiensis. Apart from two samples from Halla Arboretum on Jeju Island, all samples were derived from natural populations. Table S2. The probability of identity (PID) values for each of the 15 polymorphic loci per locus and the multi-locus values.

\section{Abbreviations}

bp: base pair; EST: expressed sequence tag; RNA: ribonucleic acid.

\section{Acknowledgements}

We thank H. Kanehara for her assistance with DNA extractions and S. Kikuchi, I. Tamaki and I. Tsuyama for help in the field.

\section{Authors' contributions}

JRPW, KC, YH and AQ devised the study and did the sample collection. JRPW designed the primers, undertook fragment analysis and genotyping. JRPW did the data analysis and wrote the manuscript. All authors participated in the draft the final manuscript. All authors read and approved the final manuscript.

\section{Funding}

This work was supported by the Japanese Society for the Promotion of Science Grant-in-Aid for Young Scientists A (Grant number 16748931) and the Chinese Special fund for basic scientific research business of central public research institutes (Grant number CAFRIFEEP201401). These funding bodies had no role in the design of the study and collection, analysis, and interpretation of data and in writing the manuscript.

\section{Availability of data and materials}

The 38,076,160 paired-end reads are deposited in the NCBI BioProject Database, Accession number: PRJNA554973. The genotype data for every individual are available on demand to the corresponding author.

\section{Ethics approval and consent to participate}

Not applicable.

\section{Consent for publication}

Not applicable.

\section{Author details}

${ }^{1}$ Department of Forest Molecular Genetics and Biotechnology, Forestry and Forest Products Research Institute, Matsunosato 1, Tsukuba, Ibaraki 305-8687, Japan. ${ }^{2}$ Division of Forest Biodiversity and Herbarium, Korea National Arboretum, Pocheon, South Korea. ${ }^{3}$ Institute of Forest Ecology, Environment and Protection, Chinese Academy of Forestry, Key Laboratory on Forest Ecology and Environmental Sciences of State Forestry and Grassland Administration, Beijing 100091, China.

Received: 23 July 2019 Accepted: 10 October 2019

Published online: 25 October 2019

\section{References}

1. Altschul SF, Gish W, Miller W, Myers EW, Lipman DJ. Basic local alignment search tool. J Mol Biol. 1990;215:403-10.

2. Brownstein MJ, Carpten JD, Smith JR. Modulation of non-templated nucleotide addition by Taq DNA polymerase: primer modifications that facilitate genotyping. Biotechniques. 1996;20:1004-6.

3. Hasegawa Y, Takata K, Tsutomu Y, Gaku H, Saitoh T. Clone identification among saplings in a natural forest of Thujopsis dolabrata var. hondae using multiplex EST-SSR analysis. J Jpn For Soc. 2015;97:261-5 (in Japanese).

4. Hayakawa T, Tomaru N, Yamamoto S. Stem distribution and clonal structure of Chamaecyparis pisifera growing in an old-growth beech-conifer forest. Ecol Res. 2004;19:411-20.

5. Hodel RGJ, et al. The report of my death was an exaggeration: a review for researchers using microsatellites in the 21st century. Appl Plant Sci. 2016;4:1600025.

6. LePage BA. A new species of Thuja (Cupressaceae) from the Late Cretaceous of Alaska: implications of being evergreen in a polar environment. Am J Bot. 2003:90:167-74.

7. Li JH, Xiang QP. Phylogeny and biogeography of Thuja L. (Cupressaceae), an eastern Asian and North American disjunct genus. J Integr Plant Biol. 2005;47:651-9.

8. Mertz M. Wood and traditional woodworking in Japan. 2nd ed. Otsu City: Kaiseisha Press; 2011.

9. Peakall ROD, Smouse PE. Genalex 6: genetic analysis in Excel. Population genetic software for teaching and research. Mol Ecol Notes. 2006;6:288-95.

10. Peng $D$, Wang $X Q$. Reticulate evolution in Thuja inferred from multiple gene sequences: implications for the study of biogeographical disjunction between eastern Asia and North America. Mol Phylogenet Evol. 2008;47:1190-202.

11. Raymond M, Rousset F. GENEPOP (version 1.2): population genetics software for exact tests and ecumenicism. J Hered. 1995;86:248-9.

12. Valiere N. GIMLET: a computer program for analysing genetic individual identification data. Mol Ecol Notes. 2002;2:377-9.

13. Wada K. The vegetation of Mt Nagisodake at the south-western part of Nagano Prefecture. Bull Inst Nat Educ Shiga Heights Shinshu Univ. 1994;31:21-6.

14. Waits $L P$, Luikart $G$, Taberlet P. Estimating the probability of identity among genotypes in natural populations: cautions and guidelines. Mol Ecol. 2001;10:249-56.

15. Worth JRP. Current distribution and climatic range of the Japanese endemic conifer Thuja standishii (Cupressaceae). Bull FFPRI. 2019;18:275-88.

16. Yang Y, Li N, Christian T, Luscombe D. Thuja sutchuenensis. The IUCN red list of threatened species. 2013; 3.T32378A2816862. Accessed 22 July 2019.

\section{Publisher's Note}

Springer Nature remains neutral with regard to jurisdictional claims in published maps and institutional affiliations.

\section{Competing interests}

The authors declare that they have no competing interests. 